\title{
Optimizing Cyber Deterrence
}

\author{
Eric Jardine \\ Assistant Professor, Political Science, Virginia Tech \\ ejardine@vt.edu
}

Preprint: Eric Jardine, 2020 “ “Optimizing Cyber Deterrence." In The Cyber Deterrence Problem, Aaron F. Brantly, ed. (New York: Rowman and Littlefield), page 87-104.

Keywords: Deterrence; cyber deterrence; optimization; cybersecurity; national security; NSA; vulnerabilities; Stuxnet; deterrence optimization; cyber war

Abstract: Cyber deterrence is not like regular deterrence. In regular deterrence, say between two nuclear powers, the development of more nukes does not make hardened silos less effective on a per unit basis. Cyber deterrence is different. Cyber deterrence is inextricably riddled with tradeoffs and interdependencies that regular deterrence lacks. This chapter outlines the essential tradeoffs between cyber deterrence by denial, punishment, entanglement and taboo. Each case example illustrates how investing heaving in one form of cyber deterrence costs, at margin, in some other category. Cyber deterrence can be optimized, but only with these essential tradeoffs in mind. 
Cyberattacks are becoming an increasingly serious threat to national security (Clarke \& Knake, 2010; Conti \& Raymond, 2018; Herr \& Schneier, 2017). In 2015, for example, it came to light that the Islamic State had attempted to infiltrate the US power grid (Bender, 2015). In 2016, Russian actors launched a well-coordinated misinformation campaign to disrupt the US presidential election (Howard, Bolsover, Kollanyi, Bradshaw, \& Neudert, 2017). In 2017, over 150 nations were affected by the WannaCry ransomware attack, which crippled unpatched machines running the Microsoft XP operating system. Critical infrastructure, such as the United Kingdom's National Health Services, was particularly affected (BBC, 2017). In 2018, Russian actors again targeted the United States, this time taking aim at the nation's power system (Sanger, 2018).

These attacks of varying severity and form on the critical national infrastructure of states illustrate a growing trend toward the weaponization of cyberspace. Malicious trends in cyberspace might be less pronounced than is commonly thought (Jardine, 2015, 2017b, 2018), but the malicious actors of today are continuing a wider pattern of increasing use of cyberattacks as a tool of warfare, espionage, sabotage, disruption that reaches as far back at the late 1980s (Healey, 2013; Warner, 2012). As more of the physical world gets linked to the Internet, the potential for rapid, far-reaching and potentially catastrophic cyberattack increases.

To counter the use of cyber as a weapon of war, older concepts of deterrence have been retooled from the nuclear age to work in the new digitally interconnected world (Libicki, 2009). The decision to attack in cyberspace is a highly calculated and rational undertaking (Aaron Franklin Brantly, 2018). This underlying rationality mirrors the basic principles that undergirded the globe-spanning Cold War between the United States and the Soviet Union, potentially making deterrence an effective mitigation strategy in cyberspace.

At its core, deterrence is about shaping an adversary's choices (Mearsheimer, 2017; T. Schelling, 1966). Successful deterrents aim to maximize an adversary's perceived costs associated with launching an attack, while also minimizing their perceived benefits. During the Cold War, the aim of military procurement, nuclear doctrine, and policy and strategy was to largely maximize the nation's deterrent. Failing to do so meant potential nuclear annihilation. With clear potential dangers due to misperception, conflict spirals and security dilemmas (Jervis, 1968), maximizing deterrence during the nuclear era often meant maximizing the inputs to deterrence, such as building more bombs, hardening more silos, developing the nuclear triad, and variously promulgating counter-value and counter-force targeting doctrines.

Cyber deterrence, I argue here, follows a fundamentally different logic. States can still try to maximize deterrence as an outcome, but cannot do so by simply maximizing the inputs to the deterrent itself. Unlike in the case of nuclear deterrence, there are essential interdependencies in cyberspace that prevent deterrence maximizing through simple input maximization. For example, hoarding zero-day vulnerabilities adds to the retaliatory arsenal of a state, thereby increasing a state's deterrent. But, failing to disclosure vulnerabilities to vendors also increases the vulnerability of the state's networks, reducing the state's deterrent position. These sort of interdependencies and feedback loops do not plague the processes of nuclear deterrence in the same way. They are largely unique features of the cyber realm. 
This simple observation necessitates a shift in both scholarly and policy thinking about deterrence. Rather than maximizing deterrence by maximizing the inputs to the deterrent, the essential interdependencies and tradeoffs in cyberspace requires that deterrence maximization follow from a process of input optimization across the various components of cyber-deterrence. This shift has non-trivial implications for how governments aim to design their cyber deterrent posture.

In what follows, I first outline a basic cyber deterrence model, leveraging Joseph Nye's notion of deterrence by denial, entanglement, retaliation and taboo (Nye, 2017). In this section, I illustrate how the interdependencies of cyberspace limit classical notions of deterrent maximization through input maximization. In the remaining sections, I provide short illustrative vignettes to point to the various interdependencies between the means of cyber deterrence. I conclude with a discussion of the implications for policy that follow closely from the proposed revision to how we think about deterrence.

\section{The Nuts and Bolts of Deterrence}

Deterrence is an old concept, predating the nuclear era or even the clear articulation of the idea (Quester, 1986). Classical deterrence doctrine tends to emphasize the credibility of retaliation, coupled with the size of the potential retaliatory action (T. Schelling, 1966; T. C. Schelling, 1981). Beyond these material factors, a host of ideational, reputational and moral factors influence an adversary's calculated decision to launch an attack (Aaron Franklin Brantly, 2018). The overall aim of a good deterrent is to increase the costs that an adversary must face, making aggressive actions, everything else being equal, less likely (A. F. Brantly, 2018). As Glenn Snyder puts it, "Deterrence is a function of the total cost-gains expectations of the party to be deterred" (Snyder, 2016, pp. 9-10).

Joseph Nye extends the early concept of deterrence into the realm of cyberspace (Nye, 2017). Although a self-acknowledged instance of conceptual stretching, Nye's discussion leverages the idea that deterrence (or dissuasion in the last two cases) can be effectively reached via: 1) the threat of punishment; 2) denial; 3) entanglement; and 4) normative taboo. Punishment — classical deterrence - involves the threat of retaliation if an opponent launches an attack. Denial involves increasing the costs that an opponent must pay to launch a successful attack. Entanglement speaks to the complex interdependencies of contemporary global governance, where an opponent can be deterred because they will be exposing themselves to negative, costly repercussions. Deterrence via normative taboo, finally, involves actors limiting themselves from launching an attack due to some combination of the internalization of norms or fear over reputational damages should they break a norm of non-use.

The various deterrent forms in Nye's framework do not necessarily work in isolation. As Nye puts it, "None of these four mechanisms of deterrence and dissuasion ... is perfect, but together they illustrate the range of means by which it is possible to reduce the likelihood of adverse acts causing harm in the cyber realm. They can complement one other [sic] in affecting actors' perceptions of the costs and benefits of particular actions" (Nye, 2017, p. 62). To put a fine point on it, an actor can be deterred from launching a malicious attack because of both a worry about 
reputation (dissuasion by taboo) and the threat of retaliation (deterrence by retaliation). Often, all four means of deterrence work together to attempt to deter unwanted aggression.

Figure 1 illustrates a simple long form game theoretic decision tree to showcase the point. An opponent has the option of either attacking or not. The actor would then, probably implicitly, calculate their potential benefits (A) from launching an attack. Benefits here could include everything from weakening an opponent and stealing valuable diplomatic or economic secrets to shoring up flagging local support through rally-around-the-flag type effects (Blainey, 1988).

Stacked against these material and perceptual gains is a bundle of costs $(\mathrm{R}, \mathrm{D}, \mathrm{E}, \mathrm{T})$ that an adversary must weigh. In the case of retaliation, taboo and entanglement, increasing values on each variable imposes more cost on an attacker (A. Brantly, 2018). These costs are based upon an assessment of the consequences of an attack. Malicious actors could worry, for example, that their action could result in retaliation and that they would need to absorb this cost should they decide to strike first. Denial is perhaps better conceptualized as a cost that occurs in the planning and execution of a potential attack. Well-defended networks can make exploitation harder and increase the costs that an attacker will need to absorb in order to launch a successful attack (Conti \& Raymond, 2018). Summed together, these variable deterrence costs get put into balance against the perceived benefits of aggression for an adversary. When costs are greater than benefits, the potential attacker is successfully deterred. When benefits predominate, the adversary will strike, causing disruption, damage and destruction.

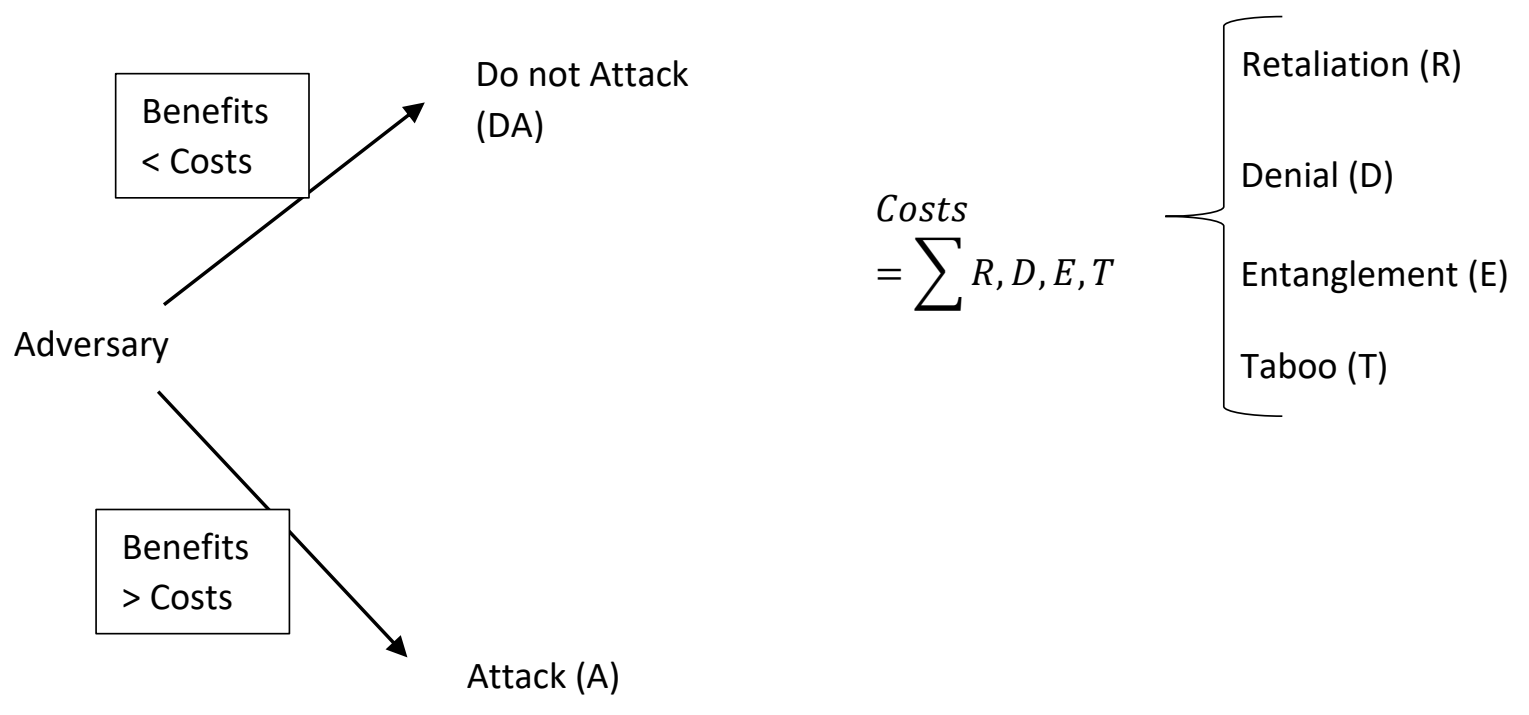

\section{Figure 1. Pathways to Cyber Deterrence}

But most of the cyber deterrence literature tends to rest upon the assumption that maximizing deterrence hinges, as it did largely during the Cold War, upon maximizing the various inputs to the deterrent. In Nye's formulation, for example, all four means of deterrence are seen as complements that work in tandem to deter aggression. The policy implication that follows most 
directly from this complementarity is the idea a state can most effectively deter aggression if it maximizes its retaliatory potential, the hardness of its networks, its entanglement with potential adversaries and the strength of any taboos of non-use.

This often implicit assumption suffices as a guide for policy only if maximizing one input value does not pull down another. That assumption was largely satisfied during the Cold War. With nuclear deterrence, the means of deterrence were largely independent. For example, a government might face a choice between building another bomb or hardening another silo due to resource limitations, but actually building another bomb would not make existing silos less hardened or vis-a-versa. Maximization of the inputs to deterrence were, therefore, effective at maximizing deterrent outcomes.

The difficulty is that this assumption does not apply particularly well in cyberspace due to a simple problem of complex interdependencies. Interdependent networks lead to complex feedback loops and gives rise to unintended second- and n-order effects. Unlike in nuclear deterrence where the means of deterrence were largely independent of each other, a state's means of cyber deterrence are highly interrelated. More problematically still, the interrelationships often manifest negatively, in the sense that a state's increase in its retaliatory capacity could actually cause positive harm to its levels of deterrence by entanglement or denial.

The implication of these interdependencies is non-trivial. Simply increasing each input to deterrence is not likely to result in the highest possible deterrent effect, as such activities regularly did — subject to resource constraints and adversary reactions — during the Cold War. Instead, maximizing deterrent outcomes in cyberspace requires more of an optimization approach. Once the existence of tradeoffs between the various means of deterrence is put at the center of the analysis, it becomes possible to speak about finding the optimal value on each deterrent input so as to maximize a state's overall ability to deter bad behavior by adversaries. In the following sections, I will present scenarios demonstrating these interdependencies in action. In each case, maximizing one input to deterrence drags down another.

\section{Hoarding Zero-Days (Punishment) vs. Disclosure (Denial)}

Patterns in the weaponization of software present the first example of a set of interdependencies that affect processes of cyberdeterrence maximization. Cyberattacks often rely upon the weaponization of vulnerabilities in software. Stuxnet, for example, is widely considered one of the first significant cyberweapons, as it was designed not just to steal information or corrupt data, but to cause physical world destruction at nuclear power facilities running specific Siemen's programmable logic controllers (PLCs) (Zetter, 2015a). The worm used four zero-day vulnerabilities to infect systems and spread surreptitiously between machines. As the worm spreads, it would look for the specific signature of the Siemen's PLCs. If it did not find any sign of the code it was looking for, it would attempt to propagate to new systems before finally deleting itself to prevent reverse engineering and discovery. Eventually, the worm found its likely intended target: The Iranian nuclear facility at Natanz, which ran the desired PLCs. Once onto the system, the worm wreaked havoc on the centrifuges and displayed misinformation to the engineers in the control booth, causing the destruction of property and the disruption of Iran's nuclear program. 
Given the clear offensive potential of zero-day vulnerabilities, governments actively collect these software flaws in order to build up their cyber-arsenals. In the US, for example, the National Security Agency (NSA) actively attempts to identify and collect zero-days for the purpose of tailored access operations (TAO). In 2013 alone, the NSA reportedly spent $\$ 25$ million purchasing zero-day vulnerabilities (EPIC, 2018). While TAO have clear espionage and even outright offensive purposes in some situations, the threat of using zero-days as a retaliatory measure in the eventuality of a cyberattack readily contributes to the nation's cyber deterrent. In this sense, the collection of zero-day vulnerabilities by government agencies such as the NSA can be viewed as increasing the potential for deterrence by threat of retaliation and punishment.

But hoarding vulnerabilities for the purpose of exploitation is not strictly similar to the process of, say, building more nuclear bombs in order to deter Soviet aggression. Every zero-day vulnerability that the NSA collects and fails to disclose through the Vulnerabilities Equities Process has the potential of undermining the US' ability to deter attacks on its system by denial, which involves increasing the costs an adversary must take to launch a successful attack. Since software weapons are really a function of flawed code, anyone who finds those flaws effectively gains access to the weapons themselves (subject to the development of an exploit, of course). Access to zero-day vulnerabilities in software, therefore, is effectively non-rivalrous. The US finding a zero-day in Microsoft Windows does not prevent Russia, China or some other potential adversary from doing the same.

The non-rivalrous nature of zero-day vulnerabilities introduces a negative interdependency between deterrence by threat of retaliation and deterrence by denial. The so-called collision or rediscovery rate, which is the measure of the proportion of zero-days found independently by two or more parties over some period of time, then becomes key. Everything else being equal, the higher the collision rate the more extreme becomes the negative interdependencies between hoarding zero-days for retaliation and disclosing zero-days for deterrence by denial. A rediscovery rate of 100 percent would mean that every cyberweapon held by the NSA would erode the nation's deterrence by denial in potentially equivalent proportion, assuming that an adversary was equally sensitive to costs from failure as to costs from potential retaliation.

In practice, empirical evidence suggests that rediscovery rates of potentially useful zero-days hover at approximately 20 percent. In 2013, for example, an individual or entity calling themselves the Shadowbrokers released a number of zero-day vulnerabilities that had supposedly been stolen from the NSA. Part of this data dump included an exploitation suite that targeted Windows operating systems and included five genuine zero-day vulnerabilities (Weaver, 2017). Of these 5 flaws, one (ESKIMOROLL) had been previously discovered in the wild and patched in 2014. The other four were seemingly unique to the NSA's arsenal (Schneier, 2017). This example suggests a potential heuristic collision or rediscovery rate of 20 percent.

A more systematic study of the rediscovery of zero-day vulnerabilities suggest a variable range of collision rates, some of which closely approximate, if not match, the 20 percent heuristic from Shadowbrokers example. One systematic study of over 200 zero-days from 2002 to 2016 by the RAND Corporation, for example, found a one-year median collision rate of 5.75 percent, with a standard deviation of 6.79 percent. The median 90-day collision rate was only 0.87 percent and the full 14-year rate amounted to 40 percent (Ablon \& Bogart, 2017). Looking at this range of zero-days, the rediscovery rate tends to be fairly low. 
Another study, looking at two browsers (Chrome and Firefox), the openSSL project and the Android mobile operating system, analyzed the rediscovery or collision rate across 4,600 vulnerabilities of critical or high severity (Herr, Schneier, \& Morris, 2017). Rediscovery of these more significant vulnerabilities was much higher than what was found in the RAND study. In this case, between 15 and 20 percent of the flaws were rediscovered at least twice within a given year. Flaws in Android, for instance, had a fairly high rediscovery rate over fairly short timeframes, with collisions occurring 13.9 percent of the time over 60 days, 20 percent of the time over 90 days, and 21 percent over 120 days (Herr et al., 2017). In this dataset, as in the heuristic example of the Shadowbrokers above, about 20 percent of the software flaws that the NSA could use as a potential retaliatory deterrent will also be in the arsenal of their adversaries and could be used as a means of attack.

Deterrence is not straightforward in cyberspace. Maximizing deterrence by trying to maximize the retaliatory potential of the NSA will fail. Upwards of 20 percent of the weapons that the NSA attempts to hoard for a rainy day are likely to be found by adversaries and could then be used to target American systems. By keeping this 20 percent of zero-days under wraps, the NSA weakens the US deterrent by diminishing the costs that an adversary would need to undertake in order to successfully target US networks and devices. Punishment and denial are interconnected. Simple maximization of deterrent outcomes by maximizing the inputs to deterrence does not work.

\section{Firmware/Hardware Exploitation (Retaliation) vs. Global Software Sales (Entanglement)}

The second example of complex interdependency limiting the effectiveness of deterrence maximization via input maximization involves global software and device sales and firmware exploitation by state agencies. This example showcases an essential interdependency between the potential for deterrence by entanglement and deterrence by retaliation.

Deterrence by entanglement is really a concern about two analytically separable worries. The first dimension is the potential for attacks to disrupt the economic status quo, thereby imposing costs on any aggressive actor who launches an attack (Keohane \& Jr., 2011; Nye, 2017). This dimension of deterrence by entanglement is somewhat more limited in the cyber realm due to problems of attribution (Lindsay, 2015), where an aggressor might still be able to benefit from the status quo simply because there is insufficient evidence to directly punish the adversary for an attack. Of course, in the eventually of a significant enough attack, the target might still disrupt an otherwise economically beneficial status quo, even if the actual perpetrator is not the sole or even intended target of any counteractions.

The second dimension of deterrence by entanglement is the potential of unintended contagion. Like with biological weapons, launching a cyberattack runs the risk of spiraling backwards and affecting initial attacker. Such a contagion could be a result of the natural propagation cycle of, say, a malicious worm such as Stuxnet or it could be the result of a more deliberate retooling of malicious code. In either event, entanglement can effectively deter a malicious actor because they are worried that the malicious program that they themselves launch will adversely affect their systems and networks in some measure. 
Generally, the more entangled (technologically interconnected) two states are, the higher the potential for contagion. If two countries use the same software platforms and share extensive data flows, then their potential for cyber contagion is quite high and deterrence by entanglement should, everything else being equal, be more likely. The clear policy implication in a world of strict deterrence maximization through input maximization would be to increase interconnections to the greatest possible extent.

Market forces tend to pressure in the direction of greater interconnection. The natural process of network formation also benefits US firms to a significant degree, as many US technology companies are early movers and tend to dominate global technology markets (Barabási, 2014; Hampson \& Jardine, 2016; Jardine, 2017a). But these natural market pressures in favor of evergreater entanglement by interconnection, and so deterrence by the same measure, are often subject to the vagaries of politics.

Even the strongest natural market forces can be hamstrung by political choice. A good example of this process, which also exemplifies the negative interdependencies between deterrence by entanglement and deterrence by retaliation, is the fallout from the process of firmware hacking by government agencies such as the NSA. In one reported account, the NSA was intercepting routers, servers, and other technologies due for export to foreign countries and reportedly implanted them with malware before resealing the factory packaging and shipping them off for global distribution (Greenwald, 2014). A similar example comes from the reported behavior of the NSA-linked Equation Group, which was hacking firmware in order to gain "God-like control of the system in a way that is stealthy and persistent even through software updates" (Zetter, 2015b).

The clear goal of these efforts was to gain greater signals intelligence (SIGINT) and to effectively maximize the ability to retaliate against any who might violate the peace and launch a cyberattack. The contribution of these NSA efforts to deterrence by retaliation and punishment are two-fold. First, greater SIGINT potential would help to resolve, to a degree, persistent problems of attribution. Such a move would increase the certainty of retaliation in response to a malicious cyber-attack by an adversary. Second, having authoritative access to American made devices could provide useful means of exploitation for government agencies should they need to retaliate for malicious attacks by an adversary. Hacking the firmware of products built by American technology companies can be seen at one level, therefore, as an otherwise effective effort to increase the potential for deterrence by retaliation and punishment.

But such efforts, at least once publicly known, also harm the growth of interconnection, reducing the likelihood of effective deterrence by entanglement. The fallout from disclosure of the NSA's firmware hacking programs for Cisco Systems is an exemplary case in point. In the quarterly report and earning conference call immediately following word of the NSA's goings-on, Cisco System's Chief Financial Office, Frank Calderone, warned that these actions had prompted a high "level of uncertainty or concern" in foreign markets (Waters, 2013). This concern led to a decline in demand for Cisco products. Across the developing world, demand fell by 12 percent. Brazil, which was a vocal antagonist in the wake of the Snowden revelations, saw a 25 percent slump in demand, while Russian demand fell 30 percent. The decline in Russian demand is 
particularly telling, as the prior three-month period had actually recorded an eight percent increase in demand for Cisco products, marking a sharp reversal (Waters, 2013).

Certainly such declines might be transitory and can be countered by good PR work, but they do showcase how maximal efforts at deterrence through the prospect of retaliation can undermine the potential to deter through entanglement. The potential for cyber-contagion declines in proportional measure as foreign use of Western ICT products and digital services goes down. Hacking the products of Western companies to gain a retaliatory edge can readily undermine any fears a potential adversary might have about becoming the victim of their own malware. Once again, simply deterrence maximization via input maximization is likely to fail due to essential interdependencies between, in this case, retaliatory potential and entanglement.

\section{Excluding Vendors (Denial) vs. Contagion (Entanglement)}

Flipping the point of reference from the last example reveals another essential interdependency, this time between deterrence by denial and deterrence by entanglement. From Russia's, Brazil's or China's perspective, it makes eminent amounts of sense to limit the purchase of ICT products and services from US technology companies if they are being dragooned by the NSA into an intelligence and potential cyberwarfare advantage. At an extreme, the rational next step for governments worried about the integrity of foreign made ICT products and services is to restrict or even prohibit use.

The US readily does just that when confronted by potentially compromised products. Such measures could take the form of security warnings for US companies. In 2012, for example, a US House Intelligence Committee headed by Mike Rogers issued a final report that warned US companies of using ICT products from Huawei and ZTE, two major Chinese technology firms. The second recommendation of the report exemplifies the thinking:

Private-sector entities in the United States are strongly encouraged to consider the long-term security risks associated with doing business with either ZTE or Huawei for equipment or services. U.S. network providers and systems developers are strongly encouraged to seek other vendors for their projects. Based on available classified and unclassified information, Huawei and ZTE cannot be trusted to be free of foreign state influence and thus pose a security threat to the United States and to our systems (Rogers \& Ruppersberger, 2012, pp. vi-vii).

At a more extreme level, the government might also restrict the use of products or services from certain foreign companies in order to prevent the exploitation of these technologies by foreign governments. As the same report concluded in its first recommendation, "U.S. government systems, particularly sensitive systems, should not include Huawei or ZTE equipment, including component parts. Similarly, government contractors - particularly those working on contracts for sensitive U.S. programs - should exclude ZTE or Huawei equipment in their systems" (Rogers \& Ruppersberger, 2012, p. vi).

A more recent example is 2017 ban on use of Kaspersky Labs (a Russian cybersecurity firm) products in US government military and civilian networks (Volz, 2017). The motive behind the 
restrictions was long-standing concern over the integrity of these products and their potential manipulation by Russian state authorities. As Democratic Senator Jeanne Shaheen noted, Kaspersky Labs software posed a "grave risk" to US security, making the law "long overdue"(Volz, 2017).

Restrictions such as these effectively harden the networks and devices used by US government agencies, departments and associated civilian contractors. Cumulatively, these steps would increase the costs that a potential adversary would need to pay in order to launch a successful attack against US networks. Product and service bans of foreign ICT companies would, therefore, contribute directly to the potential to obtain deterrence by denial. At an extreme level, this vector of deterrence by denial would be maximized by banning all foreign-made products and services, as foreign products might always come along with the potential for privileged manipulation by the country of origination or incorporation.

Such an extreme example also illustrates the potential for maximizing deterrence by denial to undermine the potential of deterrence by entanglement. Entanglement can help to deter because potentially malicious actors may worry that an attack will spread via contagion dynamics to affect their own systems, much like the spread of a biological pathogen for the purposes of warfare runs the risk of getting one's own people sick.

Stuxnet provides an interesting example of this contagion process. The worm was hyper tailored by design and intended, from everything we know, to hit Iran's nuclear program (Zetter, 2015a). The level of intelligence data needed to tailor the worm was so immense that Ralph Langner, one of those who discovered the malicious program, flippantly noted those behind the worm "probably knew the shoe size of the operator" in Natanz (BBC, 2011). Leveraging all this detail, the US and Israeli intelligence communities (reportedly) were able to design a remarkably targeted malicious program, especially given the self-propagation nature of worms.

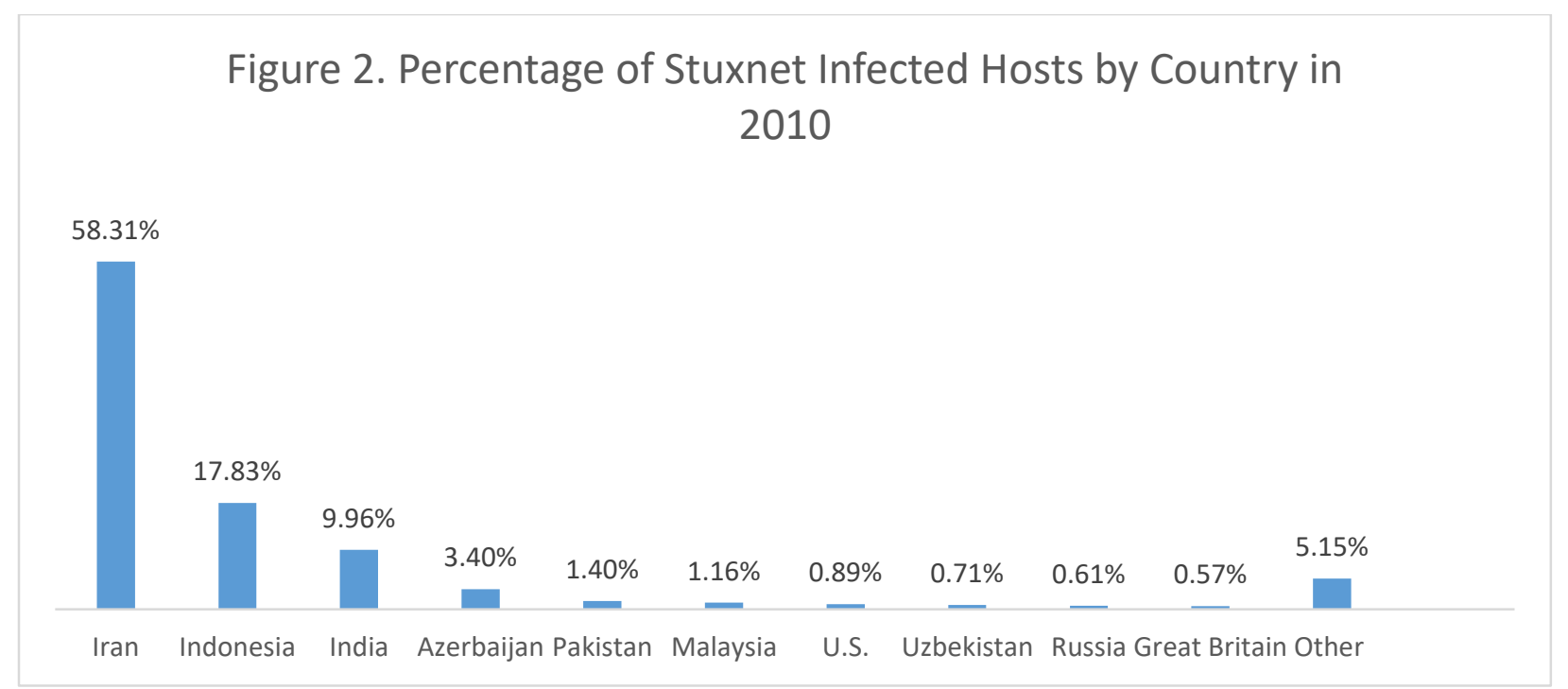

Despite building a worm that zeroed-in on its target like a heat seeking missile and which deleted itself if the Siemen's PLCs were not found on the system, even US-based hosts were still infected. Figure 2 presents data taken from Statista Research (Statista, 2018) on the global spread 
of the Stuxnet worm. During 2010, for example, 58 percent of infected hosts globally were clustered in Iran, speaking to the remarkably targeted nature of the worm. Still, the U.S. recorded 0.89 percent of infected hosts, showcasing how even a hyper targeted malicious program can circle back to affect the originator. Framed in absolute terms, for every 58 devices infected in the target country, the US suffered roughly one compromised device. Obviously, self-propagating malicious programs that are less well targeted would present an even higher risk of reciprocal contagion and very targeted malicious programs might be specifically design to cause less damage on one's own systems.

This point on reciprocity cannot be understated. If product use clusters somewhat according to nation of origin, with Russians using Kaspersky Labs software more in proportional terms than the US, then Russian manipulation of Kaspersky Labs software presents a real danger of reciprocal contagion. In contrast, if US government systems only run Symantec security products, as an example, and Russian networks do not, then a Russian attack on US government networks would need to target that potentially harder to exploit vector of attack but pose little chance of reciprocal contagion, since software use might breakdown firmly along national lines.

Maximizing deterrence by denial by banning products from other countries, therefore, can undermine the realized level of deterrence by entanglement. As before, steps intended to maximize deterrence by maximizing the cost of denial imposed upon a potential adversary can feedback and undermine deterrence by entanglement. Input optimization-not input maximization - is needed for effective deterrence maximization overall.

\section{Cyberattacks (Retaliation) vs. Non-Use Norms (Taboo)}

The final vignette of a complex interdependency involves the tradeoff between an effective retaliatory deterrent and deterrent taboos. Here, the cyber realm mirrors more closely to the nuclear. The strength of norms against nuclear use originate in some not inconsiderable measure in the historically limited use of nuclear weapons in times of war (Tannenwald, 2005, 2009). If nuclear weapons were to be used again, the norm restraining nuclear use would weaken.

The shared interconnection between norms of non-use and use of prohibited weapons highlights a fairly significant dissimilarity, however, in terms of historical record. While nuclear weapons have only been used in anger two times throughout history, cyber weapons are used with remarkable and increasing frequency. Often, as Herb Lin has pointed out, nuclear weapons are seen as a weapon of last resort, while cyberweapons are routinely employed as first step before all other forms of military technology (Lin, 2012). Norms of non-use, then, are routinely violated in the cyber realm, often first by the attack and then by the target who retaliates in so-called active defense.

But the problem is more pernicious than it might seem. Deterrence via threats of retaliation involve dimensions of both certitude and magnitude. In other words, deterrence works via threats of punishment when a potential adversary thinks that the reaction will be 1) big and 2) certain. Attribution problems clearly plague the certainty component of deterrence by retaliation (Lindsay, 2015), but a failure to respond to aggression can also shape expectations about the certainty of retaliatory punishment in the event of an attack. Ensuring that threats of retaliation 
are seen as credible and certain requires responding to cyberattacks. Often, while diplomatic finger pointing, economic sanctions or every conventional military force can be used in response to cyber-aggression (Gartzke \& Linsday, 2014), punching back in cyberspace is commonly done via reciprocal cyberattack. Tit-for-tat cyberattacks of this sort might increase the possibility of deterrence by retaliation by demonstrating a higher certitude of punishment, but undermine any sort of deterrence by taboos of non-use. Conversely, failing to respond to a cyberattack could strengthen the norm of non-use, but would weak perceptions of deterrence by retaliation.

Norms, of course, also come in variable levels of thickness. General prohibitive norms disallowing use of cyberspace as a weapon (i.e. thou shall not use) are far thicker than target- or tool-specific restrictions. It is probably most accurate to say that trends in terms of normative restrictions in cyberspace are angled toward restricting the types of allowable targets, rather than the tools that may be used or any sort of general prohibitive limitations (Valeriano \& Maness, 2015). As Nye puts it, "A more fruitful approach to arms control [via taboo] in the cyber world would develop a taboo not against types of weapons but against types of targets" (Nye, 2017, p. $61)$.

Yet even this more 'fruitful approach' suffers the same potential tradeoffs and interdependencies. Before the processes were killed by the Trump Administration, The United Nations Group of Governmental Experts (UNGGE) had been at the forefront of trying to promulgate a set of norms barring cyberattacks against certain targets. In 2015, for example, the UNGGE adopted a summative report where member states agreed to restrict what assets could be targeted by cyberweapons. As the report details, "A State should not conduct or knowingly support ICT activity contrary to its obligations under international law that intentionally damages critical infrastructure or otherwise impairs the use and operation of critical infrastructure to provide services to the public" (Nations, 2015, p. 8). These sorts of wide-ranging and consensus based efforts at norm building could help to deter cyberattacks against specific targets via normative taboo.

Critical national infrastructure has variable definitions depending the country in question. In the US, the Department of Homeland Security rates 16 sectors as part of the critical national infrastructure bundle. Health services, government services, the financial sector and energy and power obviously rank highly, but the list also includes communication infrastructure and the information technology sector (Security, 2018). These final sectors entail that attacks on the Internet itself as well as, presumably, major backbone providers or even content delivery networks could be read, likely based upon the disruption caused, as attacks on critical national infrastructure.

The implication of this definition of critical national infrastructure is twofold. First, despite the plausibly greater potential to develop taboos of targeting rather than taboos of use, targets on the normatively prohibited list are still routinely attacked, which would weaken the effectiveness of deterrence by taboo. Second, and more significantly, trying to ensure credibility of retaliatory punishment in cyberspace needs to contend with the fact that cyber-retaliation remains generally cheaper, often more effective, and usually less likely to cause human causalities than most other retaliatory options such as missile strikes or even economic sanctions. The first implication of 
these positives aspects of cyberattacks is they will often remain a tool of first use rather than a means of last resort (Lin, 2012). The second is that if an attack warrants a severe response, a cyberattack against critical infrastructure may often be better than the alternative of crippling sanctions or outright military force - at least for now, though the IoT and cyber-physical systems could change that.

The strength of deterrence by retaliation/punishment and deterrence by taboo are interdependent. Ensuring a credible retaliatory potential often requires expensive signaling, up-to-and-including actually retaliating against aggression. Since tit-for-tat (cyber-for-cyber) retaliation is largely the norm, with economic or other cross domain retaliation remaining possible (Gartzke \& Linsday, 2014), each cyberattack and response to ensure deterrence by threat of punishment undermines the strength of deterrence by normative taboo. The opposite choice, not responding to an attack, might increase the norm of non-use, but would weaken deterrence by threat of retaliation. As in the other cases, the interdependencies between deterrence by retaliation and deterrence by normative taboo disallow input maximization as an effect tool of deterrence maximization overall.

\section{Conclusions for Research and Policy}

This chapter has presented a single, overarching argument about the impossibility of maximizing overall deterrence through simply maximizing the various inputs to deterrence. Unlike in the Cold War era where the means of deterrence were largely independent from each other, the interconnection that is part and parcel of cyberspace creates negative interdependencies between the various means of cyber deterrence.

The aim of this chapter has been to show that maximizing one type of deterrent, say the ability to punish aggression via retaliation, actually undermines the strength of deterrence by denial. No analogous interdependencies exist in nuclear deterrence. The policy implications of this difference are non-trivial. Policy makers need to think more in complex system terms, rather than in terms of linear aggregations. Choosing to hoard zero-day vulnerabilities might be the best deterrent option, but hoarding every discovered vulnerability will, at some point, harm the ability to impose costs on a potential adversary via denial. Maximizing cyber deterrence, in other words, is really about optimizing the various inputs to the nation's deterrent.

A few implications are particularly interesting for both policy makers and those doing research on cyber deterrence. The first is that the interdependencies outlined here are likely only half of the equation. Each set of linkages above showed how increasing one means of deterrence could draw down another in some measure, effectively creating negative interdependencies. Yet positive interdependencies also likely exist. For example, increasing the resilience of a nation's networks might increase deterrence by denial, but it would also likely help to develop a norm of non-use (since fewer attacks might happen) and increase deterrence by taboo. These positive interdependencies make the issue of optimization even more important, as they could fundamentally change the cost-benefit calculus for policy makers.

Another implication of note is the likely lack of symmetry in the interdependencies between means of deterrence. In each case above, a plausible argument could be made for the idea that 
increasing one reduces the other and vis-a-versa. However, it is by no means as clear that the relationships are symmetrical. Increasing cyber deterrence via hoarding 10 percent more zerodays could reduce the effectiveness of deterrence by denial by 2 percent $(20 \%$ of $10 \%$ ). Conversely, disclosing 10 percent more vulnerabilities to vendors might not reduce the effectiveness of deterrence by threat of retaliation by an equivalent amount. Similar changes to one form of deterrence, in other words, might have dissimilar effects on the other types.

Lastly, there is a highly probable state of non-linearity at play. Complex systems are marked by non-linear moves, either discrete, logarithmic or exponential. Small changes to one of the means of deterrence might, therefore, result in initially small changes in another category. But the next set of equivalently small changes might suddenly start to matter a lot more, as non-linear effects build in the system.

Overall, the chapter is meant as a foundation for subsequent research and policy development. Recognizing that input maximization cannot lead to maximal cyber deterrence is important. Moving from this recognition via a deliberate process of simulation and optimization is the essential next step that will require civilian-military coordination, data analytics and trial and error. As more physical systems become integrated into cyberspace, the price of failure will continue to increase and the need to get cyber deterrence right grows ever more important. 


\section{Works Cited}

Ablon, L., \& Bogart, T. (2017). Zero Days, Thousands of Nights: The Life and Times of Zero-Day Vulnerabilities and Their Exploits. Retrieved from Santa Monica, Calif: https://www.rand.org/pubs/research reports/RR1751.html

Barabási, A.-L. (2014). Linked: How Everything is Connected to Everything Else and What it Means for Business, Science, and Everyday Life. New York: Basic Books.

BBC. (2011). US and Israel were behind Stuxnet claims researcher. BBC News. Retrieved from https://www.bbc.com/news/technology-12633240

BBC. (2017). NHS 'could have prevented' WannaCry ransomware attack. British Broadcasting Corporation. Retrieved from https://www.bbc.com/news/technology-41753022

Bender, J. (2015). 'They'd love to do damage': The FBI says ISIS wants to go after one of America's biggest vulnerabilities. Business Insider. Retrieved from https://www.businessinsider.com/isisand-hacking-us-power-grid-2015-10

Blainey, G. (1988). The causes of war. New York, N.Y.: Free Press.

Brantly, A. (2018). Conceptualizing Cyber Deterrence by Entanglement. Retrieved from https://papers.ssrn.com/sol3/papers.cfm?abstract id=2624926

Brantly, A. F. (2018, 29 May-1 June 2018). The cyber deterrence problem. Paper presented at the 2018 10th International Conference on Cyber Conflict (CyCon).

Brantly, A. F. (2018). DECISION TO ATTACK : military and intelligence cyber decision-making. [S.I.]: UNIV OF GEORGIA PRESS.

Clarke, R. A., \& Knake, R. K. (2010). Cyberwar: The Next Threat To National Security and What to do About It. New York: Harper Collins.

Conti, G., \& Raymond, D. (2018). On cyber : towards an operational art for cyber conflict: Kopidion Press.

EPIC. (2018). Vulnerabilities Equities Process. Retrieved from https://epic.org/privacy/cybersecurity/vep/

Gartzke, E., \& Linsday, J. (2014). Cross-Domain Deterrence: Strategy in an Era of Complexity. Paper presented at the International Studies Association, Toronto, CA. https://quote.ucsd.edu/deterrence/files/2014/12/EGLindsay CDDOverview 20140715.pdf

Greenwald, G. (2014). Glenn Greenwald: how the NSA tampers with US-made internet routers. The Guardian. Retrieved from https://www.theguardian.com/books/2014/may/12/glenngreenwald-nsa-tampers-us-internet-routers-snowden

Hampson, F. O., \& Jardine, E. (2016). Look Who's Watching: Surveillance, Treachery and Trust Online (1 ed.). Waterloo: CIGI Press/ McGill-Queen's University Press.

Healey, J. (Ed.) (2013). A Fierce Domain: Conflict in Cyberspace, 1986 to 2012. Washington, D.C. : Atlantic Council.

Herr, T., \& Schneier, B. (2017). Taking stock: Estimating vulnerability rediscovery.

Herr, T., Schneier, B., \& Morris, C. (2017). Taking Stock: Estimating Vulnerability Rediscovery. Retrieved from Cambridge, MA:

https://www.belfercenter.org/sites/default/files/files/publication/Vulnerability\%20Rediscovery \%20\%28belfer-revision\%29.pdf

Howard, P. N., Bolsover, G., Kollanyi, B., Bradshaw, S., \& Neudert, L.-M. (2017). Junk News and Bots during the U.S. Election: What Were Michigan Voters Sharing Over Twitter? Retrieved from Oxford, UK:

Jardine, E. (2015). Global Cyberspace is Safer than you Think: Real Trends in Cybercrime. Global Commission on Internet Governance Paper Series(16), 1-22.

Jardine, E. (2017a). 'Something is rotten in the state of Denmark:' Why the Internet's advertising business model is broken. 2017. doi:10.5210/fm.v22i7.7087 
Jardine, E. (2017b). Sometimes Three Rights Really Do Make a Wrong: Measuring Cybersecurity and Simpson's Paradox. Paper presented at the 16th Annual Workshop on the Economics of Information Security, La Jolla, California.

Jardine, E. (2018). Mind the denominator: towards a more effective measurement system for cybersecurity. Journal of Cyber Policy, 1-24. doi:10.1080/23738871.2018.1472288

Jervis, R. (1968). Hypotheses on Misperception. World Politics, 20(3), 454-479. doi:10.2307/2009777

Keohane, R. O., \& Jr., J. S. N. (2011). Power and Interdependence: World Politics in Transition (4 ed.). New York: Pearson.

Libicki, M. C. (2009). Cyberdeterrence and Cyberwar. Santa Monica, CA: RAND Corporation.

Lin, H. (2012). Escalation Dynamics and Conflict Termination in Cyberspace. Strategic Studies Quarterly, 6(3), 46-70.

Lindsay, J. R. (2015). Tipping the scales: the attribution problem and the feasibility of deterrence against cyberattack. Journal of Cybersecurity, 1(1), 53-67. doi:10.1093/cybsec/tyv003

Mearsheimer, J. J. (2017). Conventional deterrence.

Nations, U. (2015). Group of Governmental Experts on Developments in the Field of Information and Telecommunications in the Context of International Security. Retrieved from http://undocs.org/A/70/174

Nye, J. S. (2017). Deterrence and Dissuasion in Cyberspace. International Security, 41(3), 44-71. doi:10.1162/ISEC_a_00266

Quester, G. H. (1986). Deterrence before Hiroshima : the airpower background of modern strategy. New Brunswick (U.S.A.): Transaction Books.

Rogers, M., \& Ruppersberger, D. (2012). Investigative Report on the U.S. National Security Issues Posed by Chinese Telecommunications Companies Huawei and ZTE. Retrieved from Washington, D.C.:

Sanger, D. (2018). Russian Hackers Appear to Shift Focus to U.S. Power Grid. New York Times. Retrieved from https://www.nytimes.com/2018/07/27/us/politics/russian-hackers-electric-grid-elections. html

Schelling, T. (1966). Arms and influence: Green Wood.

Schelling, T. C. (1981). The strategy of conflict.

Schneier, B. (2017). Zero-Day Vulnerabilities against Windows in the NSA Tools Released by the Shadow Brokers. Retrieved from https://www.schneier.com/blog/archives/2017/07/zeroday vulner.html

Security, D. o. H. (2018). Critical Infrastructure Sectors. Retrieved from https://www.dhs.gov/criticalinfrastructure-sectors

Snyder, G. H. (2016). Deterrence and defense. Princeton: Princeton University Pres.

Statista. (2018). Percentage of Stuxnet Infected Hosts by Country in 2010. In.

Tannenwald, N. (2005). Stigmatizing the Bomb: Origins of the Nuclear Taboo. International Security, 29(4), 5-49. doi:10.1162/isec.2005.29.4.5

Tannenwald, N. (2009). The nuclear taboo : the United States and the non-use of nuclear weapons since 1945.

Valeriano, B., \& Maness, R. C. (2015). Cyber war versus cyber realities : cyber conflict in the international system. New York: Oxford University Press.

Volz, D. (2017). Trump Signs into Law U.S. Government Ban on Kaspersky Law Software. Reuters. Retrieved from https://www.reuters.com/article/us-usa-cyber-kaspersky/trump-signs-into-lawu-s-government-ban-on-kaspersky-lab-software-idUSKBN1E62V4

Warner, M. (2012). Cybersecurity: A Pre-history. Intelligence and National Security, 27(5), 781-799. doi:10.1080/02684527.2012.708530 
Waters, R. (2013). Cisco Cites Emerging Markets Backlash on NSA Leaks for Sales Slump. Financial Times. Retrieved from https://www.ft.com/content/445c67ce-4cb1-11e3-958f00144feabdc0?siteedition=intl\#axzz2kZimfcvz

Weaver, N. (2017). Is the NSA Doing More Harm Than Good in Not Disclosing Exploits? Retrieved from https://foreignpolicy.com/2017/09/25/is-the-nsa-doing-more-harm-than-good-in-notdisclosing-exploits-zero-days/

Zetter, K. (2015a). Countdown to zero day: Stuxnet and the Launch of the World's First Digital Weapon. New York: Broadway Books.

Zetter, K. (2015b). How the NSA's Firmware Hacking Works and Why It's So Unsettling. Wired. Retrieved from https://www.wired.com/2015/02/nsa-firmware-hacking/ 